\title{
Authenticity and Its Adaptive and Maladaptive Relations
}

\section{Djurdja Grijak}

Technical Faculty, Mihajlo Pupin, University of Novi Sad, Zrenjanin, Serbia

\section{Email address:}

djurdja.grijak@gmail.com

\section{To cite this article:}

Djurdja Grijak. Authenticity and Its Adaptive and Maladaptive Relations. Psychology and Behavioral Sciences.

Vol. 8, No. 2, 2019, pp. 33-37. doi: 10.11648/j.pbs.20190802.11

Received: March 15, 2019; Accepted: April 26, 2019; Published: May 15, 2019

\begin{abstract}
The aim of the research was to evaluate the factors of authenticity (Self-alienation, Accepting external influence and Authentic living) in their nomological network including positive and negative affect, self-esteem, psychological distress and psychological wellbeing. The sample were 206 students (93.2\% females) from the University in Novi Sad. Instruments used were Authenticity Scale, Rosenberg Self-Esteem Scale - RSE, The Positive and Negative Affect Schedule - PANAS and Mental Health Inventory - 38 - MHI-38. Results implied that Authentic living has adaptive relations with self-esteem and positive affectivity, while Self-alienation and Accepting external influences has adaptive relations with psychological distress. Maladaptive relations has Self-alienation with self-esteem, positive affectivity and psychological well-being (overall positive affectivity, emotional relations and satisfaction with life) and Accepting external influences has with positive affectivity. This study is significant for further illumination of the role of authenticity in mental health.
\end{abstract}

Keywords: Authenticity, Maladaptive, Adaptive, Mental Health, Self-Esteem

\section{Introduction}

In humanistic personality theories, authenticity, as a subjective awareness of life aligned with personal values and beliefs, is the key characteristic of adaptive functioning and wellbeing [1]. When defining authenticity in general, the starting point, for a long time, was the lack of authenticity or "false self" behavior, which was given the most attention in clinical, social-psychological and developmentalpsychological literature wherein theorists and researchers discussed self-deception and deception, self-monitoring, secrecy, false tendencies and respect. Analysis of language used in researches of authenticity is also rather interesting: verbs - cloaking, forging, pretending, hiding and such; adjectives - impossible, avoiding, false, fake, two-faced, manipulative, calculated, pretentious and such; nouns hypocrite, fraud, phony and such.

Rogers describes that individuals in stress tend to show progress in therapeutic process and move away from the desire and need to please others - they no longer wish to be what they should be, regardless of whether that demand was made by their parent or their culture and the individual moves towards a growing autonomy and becomes responsible for themselves by making decisions on which activities and behaviors have meaning [2]. According to Rogers, authenticity is rooted in one's self, but not as a static self-representation. Rather, authenticity may be conceptualized as a dynamic process whereby one's potentials, characteristics, emotions, values and motivation are discovered and explored, accepted, imbued with meaning or purpose, and actualized [3]. Authenticity in psychotherapy means that the therapist is his actual self during his encounter with his client. The therapist encounters his client directly, without facade, without denying himself or hiding behind professionalism. However, this reality is not easy to reach. Authenticity is the key factor for the development of trust, and therefore the idea on acceptance and empathy from the therapist can be truly efficient only if the client perceives them as authentic. Personal presence of the therapist is also reflected in his choice of techniques that need to be authentic, i.e. in accordance to the therapist's personality if they are to be efficient for the client. Rogers thus emphasizes respect for each therapist's personal style. The therapist can never bring the client further than where he is himself as a person. This is why it is important that the therapist is an authentic, i.e. psychologically well-developed and integrated individual so that the client could achieve the same.

One of the best definitions appeared within humanistic 
psychology, where authenticity, its content and boundaries were clearly defined. Wood and associates [4] constructed an Authenticity Scale based on the humanistic definition of authenticity as a result of an agreement between different counseling, clinical and empirical perspectives. BarretLennard [5] claimed that authenticity consists of three elements - person's primary experience, their symbolized awareness and their outward behavior and communication. This tripartite construct of authenticity involves three characteristics - lack of self-alienation including identity with personal beliefs, feelings, inherited tendencies and objective realities; authentic living as an awareness of life in accordance to identity and not accepting external influences when they go against personal values and beliefs. The model presupposes that authenticity implies harmony between these three elements. Thus, a person is authentic when their identity is in accordance with reality (low self-alienation), when they act in accordance with reality (high authentic living) and when they do not accept external influences that alter their self-perception or hinder their authentic behavior (low accepting external influences). The Authenticity Scale appears to have good psychometric properties. To the best of our knowledge, there are several adaptation of this instrument - Iranian [6], Turkish [7], French [8] and Serbian [9]. All adaptations of the Authenticity Scale showed that the instrument in question is reliable and valid. Authenticity Scale is an instrument with excellent psychometric properties, which can be used to assess three separate, but closely connected components of authenticity: Authentic living, Accepting external influence and Self-alienation which are all based on the authenticity factor.

Wood and associates have in their research concluded that self-alienation is positively related to anxiety and stress, and negatively related to self-esteem, satisfaction with life, positive affect, autonomy, positive relationships, personal growth, self-acceptance and gratitude and negatively connected to stress and negative affect. In addition, authentic living is a good predictor of stress and negative affect, as well as positive changes following domestic violence. Accepting external influences is positively related to anxiety, stress and negative affect, and negatively related to selfesteem, satisfaction with life, positive affect, autonomy, positive relationships, personal growth and self-acceptance. Other researches have shown that authentic living is positively related to benefit [10], high self-esteem [11], satisfaction with life [12], and negatively related to anxiety and stress [13] and psychological vulnerability [14].

From the consulting aspect, authenticity is negatively related to verbal defense [15]. Inauthentic behavior can also be an adaptive response, especially in social environments where concealment is necessary for survival [16]. Authenticity is in most researches defined as the basis of psychological wellbeing, while clinical distress is a consequence occurring when inauthenticity becomes conscious [17]. A research done on Turkish students [18] revealed the existence of adaptive relations between subjective happiness and authentic living and maladaptive relations with self-alienation and accepting external influences, i.e. self-alienation and accepting external influences result in decreased subjective happiness and life satisfaction while authentic living leads to subjective happiness. Students who live authentically will more probably experience subjective happiness and satisfaction with life. This further confirmed that authentic living reflects the sense of authenticity, while self-alienation and accepting external influences reflect inauthenticity [19].

This research aimed to evaluate the factors of authenticity (Authentic living, Accepting external influence and Selfalienation) in their nomological network including positive and negative affect, self-esteem, psychological distress and psychological wellbeing. The starting assumption was that the dimensions of authenticity will have different relations to self-esteem, psychological distress and psychological wellbeing.

\section{Method}

\subsection{Sample and Procedure}

The research sample was comprised of 206 students (93.2\% females) from the University in Novi Sad, Business Academy in Novi Sad and State University in Novi Pazar. The average age of respondents was $22.58(S D=5.19$, age span 18-39). The participation in study was voluntary and participants were advised that they are free to withdraw at any time. As it was a paper-and-pencil survey, all instruments were given after lectures during academic year 2014/15. After completion of the survey, participants were debriefed on the nature of the research and all questions were answered.

\subsection{Instruments}

Authenticity. The Authenticity scale [9] is a 12-item questionnaire using seven-point Likert scale. The Authenticity scale consists of three subscales - Authentic living, Accepting external influence and Self-alienation. The reliability of Scale's Serbian adaptation was - for Authentic living $\alpha=.63 \quad(\mathrm{M}=5.73, \quad \mathrm{SD}=3.77)$, Accepting external influence $\alpha=.76(\mathrm{M}=2.62, \mathrm{SD}=4.84)$ and Self-alienation $\alpha=.72(\mathrm{M}=2.74, \mathrm{SD}=5.26)$.

Self-esteem. The Rosenberg Self-Esteem Scale - RSE [20] is commonly 10-item questionnaire using a four-point Likert scale. The reliability for RSE was $\alpha=.89 \quad(M=29.75$, $\mathrm{SD}=6.93$ ).

Affect. The Positive and Negative Affect Schedule PANAS [21]. The PANAS consists of two scales, one assessing the positive affect (10 items) and the other assessing the negative affect (10 items) using five-point Likert scale. The results were ranked from 10 to 50 and a lesser score indicated lower positive, i.e. negative affect. Reliability for positive affect was $\alpha=.83 \quad(M=33.07$, $\mathrm{SD}=6.86)$, and for negative affect $\alpha=.88 \quad(\mathrm{M}=19.61$, $\mathrm{SD}=7.19$ ).

Mental health. Mental Health Inventory - 38 - MHI-38 
[22] includes 38 items divided into six subscales, consisting of two general scales, Psychological distress (Anxiety - 9 items, Depression - 4 items, Loss of behavioral/emotional control - 9 items) and Psychological well-being (General positive affect - 10 items, Emotional ties -2 items and Satisfaction with life -1 item). The MHI-38 use five- and six-point Likert scale. Reliability for Anxiety was $\alpha=.89$ $(\mathrm{M}=24.91, \mathrm{SD}=7.68)$, Depression $\alpha=.83(\mathrm{M}=8.96, \mathrm{SD}=3.52)$, Loss of control over behavior/emotional control $\alpha=.73$ $(\mathrm{M}=23.27, \quad \mathrm{SD}=5.80), \quad$ General positive affect $\alpha=.88$ $(\mathrm{M}=39.01, \quad \mathrm{SD}=8.39)$, Emotional ties $\alpha=.60 \quad(\mathrm{M}=7.97$, $\mathrm{SD}=2.59$ ). The subscale Emotional ties has only two items and it could be the cause of low reliability. The subscale Satisfaction with life has only one item with descriptive statistics $(\mathrm{M}=4.13, \mathrm{SD}=1.14)$.

\section{Results}

\subsection{Descriptive Statistics}

The descriptive statistics for factor of authenticity and additional variables of interest are shown in Table 1 .

Table 1. Descriptive statistics for authenticity factors and variables of interest.

\begin{tabular}{lll}
\hline & $\boldsymbol{M}$ & $\boldsymbol{S D}$ \\
\hline Authentic living & 5.73 & 3.77 \\
Accepting external influence & 2.62 & 4.84 \\
Self-alienation & 2.74 & 5.26 \\
\hline
\end{tabular}

\begin{tabular}{lll}
\hline & $\boldsymbol{M}$ & $\boldsymbol{S D}$ \\
\hline Positive affect & 33.07 & 6.86 \\
Negative affect & 19.61 & 7.19 \\
Self-esteem & 29.75 & 6.93 \\
Anxiety & 24.91 & 7.68 \\
Depression & 8.96 & 3.52 \\
Loss of behavior/emotional control & 23.27 & 5.80 \\
General positive affect & 39.01 & 8.39 \\
Emotional ties & 7.97 & 2.59 \\
Satisfaction with life & 4.13 & 1.14 \\
\hline
\end{tabular}

Note: $\mathrm{N}=206$

\subsection{Confirmatory Factor Analysis}

CFA was tested the same models that were evaluated in the original research [4]. Firstly, one-factor model was tested to evaluate whether the Authenticity Scale represents a onedimensional, general measure of authenticity. The results shown in Table 2 show that the values of all the indicators of this model fit are below acceptable limits. Then followed the evaluation of tripartite model of the Authenticity Scale as the theoretically expected scale structure according to the assumptions of the original authors. Values of all indicators point to a good model. Then followed the bi-factor model in which three orthogonal factors were specified (Authentic living, Accepting external influence and Self-alienation) together with one superordinate factor of authenticity which is saturated by all 12 items. As with the original scale, this model showed the best indicators, whose values fall within the span of good ones.

Table 2. Indicators of fit in confirmatory factor analysis.

\begin{tabular}{|c|c|c|c|c|c|c|c|c|c|}
\hline & $\chi^{2}$ & df & $\mathbf{p}$ & $\chi^{2} / \mathrm{df}$ & RMSEA $(90 \% \mathrm{CI})$ & SRMR & CFI & GFI & NFI \\
\hline 1-factor model & 315.55 & 54 & .00 & 5.84 & $.15(.14-.17)$ & .11 & .73 & .80 & .69 \\
\hline 3-factor model & 95.57 & 51 & .00 & 1.87 & $.06(.04-.08)$ & .05 & .95 & .93 & .90 \\
\hline 4-factor model & 55.03 & 36 & .02 & 1.52 & $.05(.02-.08)$ & .04 & .98 & .96 & .94 \\
\hline Factor intercorrelations & 1. & 2. & 3. & & & & & & \\
\hline 1. Self-alienation & 1 & .436 & -.182 & & & & & & \\
\hline 2. Accepting external influence & .436 & 1 & -.242 & & & & & & \\
\hline 3. Authentic living & -.182 & -.242 & 1 & & & & & & \\
\hline
\end{tabular}

Note: $\mathrm{N}=206$; 1 -factor $=$ all the items saturate one factor; 3 -factor $=$ three theoretically presupposed, correlated factors Authentic living, Accepting external influence and Self-alienation; 4-factor = three theoretically correlated factors and one superordinate authenticity factor; RMSEA = Root mean square error of approximation; $\mathrm{SRMR}=$ Standardized root mean square residual; CFI = Comparative fit index; GFI $=$ Goodness-of-fit index; NFI = Normed fit index.

\subsection{Correlations of Factors of Authenticity}

Pearson's coefficients of correlations between factors of authenticity and other variables of mental health are shown in Table 3 .

Table 3. Correlations between factors of authenticity and other variables.

\begin{tabular}{|c|c|c|c|c|c|c|c|c|c|c|c|c|}
\hline & \multirow{3}{*}{ P.A. } & \multirow{3}{*}{ N.A. } & \multirow{3}{*}{$\mathbf{S}$} & \multicolumn{9}{|c|}{ MHI - 38} \\
\hline & & & & \multicolumn{3}{|c|}{ Psychological distress } & \multicolumn{5}{|c|}{ Psychological well-being } & \multirow{2}{*}{ MHI } \\
\hline & & & & A & D & LC & PD & OPA & ER & SL & PWB & \\
\hline Authentic living & $.25 * *$ & -.103 & $.32 *$ & -.08 & -.1 & -.1 & -.88 & .1 & .03 & .01 & .89 & .09 \\
\hline Accepting external influence & $-.13 *$ & .03 & -.08 & $.22 * *$ & $.13 *$ & $.14^{*}$ & $.17 * *$ & $-.13 *$ & .05 & -.07 & -.103 & $.15^{*}$ \\
\hline Self-alienation & $-.29 * *$ & $.25 * *$ & $-.18 * *$ & $.36 * *$ & $.31 * *$ & $.36^{* *}$ & $.37 * *$ & $-.31 * *$ & $-.22 * *$ & $-.14 *$ & $-.32 * *$ & $.37 * *$ \\
\hline M & 33.07 & 19.61 & 29.75 & 24.91 & 8.96 & 23.27 & 57.14 & 39.01 & 7.97 & 4.13 & 51.11 & 106.48 \\
\hline SD & 6.86 & 7.19 & 6.93 & 7.68 & 3.52 & 5.80 & 16.04 & 8.39 & 2.59 & 1.14 & 10.64 & 23.57 \\
\hline
\end{tabular}

Note: N=206; P.A.-positive affect; N.A. - negative affect; S - self-esteem; MHI - 38 - Mental Health Inventory-38, A- Anxiety, D - Depression, LC - Loss of control over behavior/emotional control, PD- Psychological distress, OPA - Overall positive affect, ER - Emotional relations, SL- Satisfaction with life, PWB - Psychological well-being, MHI - Mental health index, ${ }^{*} \mathrm{p}<.05 ; * * \mathrm{p}<.01$

The correlations show that each of the authenticity factors have different relations with positive and negative affect, 
self-esteem, psychological distress and psychological wellbeing. Authentic living is in positive correlation with higher positive affectivity and higher self-esteem. Accepting external influences is in negative correlation with positive affectivity and general positive affectivity, and in positive correlation with psychological distress (Anxiety, Depression and Loss of behavior/emotional control). Self-alienation is in negative correlation with lower positive affectivity, selfesteem and psychological well-being (General positive affect, Emotional ties and Satisfaction with life) and in positive correlation with psychological distress (Anxiety, Depression and Loss of behavior/emotional control).

\section{Discussion}

This research aimed to evaluate the factors of authenticity (Self-alienation, Accepting external influence and Authentic living) in their nomological network including positive and negative affect, self-esteem, psychological distress and psychological wellbeing. Humanistic psychology proposed factors of authenticity [5] and Authenticity scale [4] measured them. The starting assumption was that the dimensions would have different relations to self-esteem, psychological distress and psychological wellbeing. The results of this study may contribute to clarification of the complex relationship between authenticity and mental health [1].

Rogers [3] defined authenticity as a dynamic process rooted in one's self and whereby one's potentials, characteristics, emotions, values and motivation are discovered and explored, accepted, imbued with meaning or purpose, and actualized. This is also one of the bases of a definition of authenticity within humanistic psychology. Barret-Lennard [5] defined authenticity as a tripartite construct which implies harmony between three elements lack of self-alienation including identity with personal beliefs, feelings, inherited tendencies and objective realities; authentic living as an awareness of life in accordance to identity and not accepting external influences when they go against personal values and beliefs [4]. A person is authentic when their identity is in accordance with reality (low selfalienation), when they act in accordance with reality (high authentic living) and when they do not accept external influences that alter their self-perception or hinder their authentic behavior (low accepting external influences). In this study, higher order factor structure had satisfactory fit reflecting a multidimensional conceptualisation of authenticity. Correlations between factors (Self-alienation is in negative correlation with Authentic living $(r=-.182)$ and in positive correlation with Accepting external influences $(\mathrm{r}=.436))$ suggest adaptive and maladaptive dimensions of authenticity. Results also showed that Authentic living had positive correlations with positive affectivity $(\mathrm{r}=.25)$ and selfesteem $(\mathrm{r}=.32)$ while Self-alienation had negative correlations with same variables $(\mathrm{r}=-29 ; \mathrm{r}=-18)$ and Accepting external influences had negative correlation with positive affectivity $(\mathrm{r}=-\mathrm{.13})$. In addition, Self-alienation had negative correlation with psychological well-being $(\mathrm{r}=-.32)$. On the other hand, psychological distress was in positive relation with Self-alienation $(\mathrm{r}=.37)$ and Accepting external influences $(\mathrm{r}=.17)$. This further implies that Authentic living has adaptive relations with self-esteem and positive affectivity, while Self-alienation and Accepting external influences has adaptive relations with psychological distress. Maladaptive relations have Self-alienation with self-esteem, positive affectivity and psychological well-being (overall positive affectivity, emotional relations and satisfaction with life) and Accepting external influences with positive affectivity. This might mean that students who live authentically (high Authentic living) will more probably experience self-esteem and positive emotions, students whose identity is distant from reality (high Self-alienation) and who accept external influences that are against personal values and beliefs (high Accepting external influences) will more probably experience psychological distress. These results confirmed previous researches [1, 3, 11, 12].

This study had several limitations. A suggestion for further research may be related to the research sample - its size, age and gender structure as well as clinical population. It is also recommended that future research should use multiple authenticity measures, in order to gain a more holistic view of authenticity as a multidimensional construct with maladaptive and adaptive aspects.

\section{Conclusion}

Results of this study contribute to factor analysis of authenticity measures. Authenticity is defined as tripartite construct with three factors - Authentic living, Self-alienation and Accepting external influences. Self-alienation and Accepting external influences are in positive intercorrelation and in negative correlation with Authentic living. This suggested two different sides of authenticity and is confirmed by results of their relation with different variables of mental health. While Authentic living is in positive relation with self-esteem, positive affectivity and psychological wellbeeing, Self-alienation and Accepting external influences are in positive correlation with negative affectivity and psychological distress.

We can conclude that authenticity has adaptive (Authentic living) and maladaptive (Self-alienation and Accepting external influences) relations with variables of mental health. This study is significant for further illumination of the role of authenticity in mental health.

\section{References}

[1] Grijak, Đ. (2017b). Authenticity as a predictor of mental health. Klinička psihologija, 10, 1-2, 23-34.

[2] Klipfel, K. M. (2015). Authenticity and Learning: Implications for Reference Librarianship and Information Literacy Instruction. College \& Research Libraries, 76, 1, 1930. 
[3] Rogers, C. R. (1961). On becoming a person: A therapist's view of psychotherapy. London: Constable.

[4] Wood, A. M., Linley, P. A., Maltby, J., Baliousis, M., Joseph, S. (2008). The authentic personality: A theoretical and empirical conceptualization and the development of the Authenticity Scale. Journal of Counseling Psychology 55(3), 385-399.

[5] Barrett-Lennard, G. T. (1998). Carl Rogers' helping system: Journey and substance. London: Sage.

[6] Shamsi, A., Ghamarani, A., Samadi, M., Ahmadzadeh M. (2012). The Study Of The Validity And Reliability Of The Authentic Personality Scale. Journal Of Psychological Models And Methods, 2, 8, 87-99.

[7] İlhan, T., Özdemir, Y (2013). Adaptation of Authenticity Scale to Turkish: A validity and Reliability Study. Turkish Psychological Counseling and Guidance Journal, 5(40), 142153.

[8] Grégoire, S., Baron, L., Ménard, J., Lachance, L. (2014). The Authenticity Scale: Psychometric Properties of a French Translation and Exploration of Its Relationships with Personality and Well-Being. Canadian Journal of Behavioural Science, 46(3), 346-355.

[9] Grijak, Đ. (2017a). Psychometric evaluation of the Authenticity Scale on the sample of students in Serbia. Psihologija, 50(1), 85-99.

[10] Neff, K. D., \& Suizzo, M. A. (2006). Culture, power, authenticity and psychological well-being within romantic relationships: A comparison of European American and Mexican Americans. Cognitive Development, 21, 441-457.

[11] Neff, K. D., \& Harter, S. (2002). The authenticity of conflict resolutions among adult couples: Does women's otheroriented behavior reflect their true selves? Sex Roles, 47, 403417.

[12] Lopez, F. G., Rice, K. G. (2006). Preliminary development and validation of a measure of relationship authenticity. Journal of Counseling Psychology, 53, 362-371.
[13] Sheldon, K. M. (2004). Integrity (honesty/authenticity). In C. Peterson \& M. E. P. Seligman (Eds.), Character strengths and virtues. New York: Oxford University Press.

[14] Satıcı, S. A., Kayış, R., \& Akın, A. (2013). Predictive role of authenticity on psychological vulnerability in Turkish university students. Psychological Reports: Mental \& Physical Health, 112(2), 519-528

[15] Lakey, C. E., Kernis, M. H., Heppner, W., L., \& Lance, C. E. (2008). Individual differences in authenticity and mindfulness as predictors of verbal defensiveness. Journal of Research in Personality, 42, 230-238.

[16] Robinson, O. C., Lopez, F., Ramos, K. \& Nartova-Bochaver, S. (2013). Authenticity, social context and wellbeing in the USA, England, and Russia: A three country comparative analysis. Journal of Cross-Cultural Psychology, 44, 719-737.

[17] Joseph, S., Linley, P. A. (2005). Positive adjustment to threatening events: An organismic valuing theory of growth through adversity. Review of General Psychology, 9, 262-280.

[18] Sariçam, H. (2015). Life Satisfaction: Testing a Structural Equation Model Based on Authenticity and Subjective Happiness. Polish Psychological Bulletin, 46(2), 278-284. DOI - 10.1515/ppb-2015-0034

[19] Pinto, D. G., Maltby, J., Wood, A. M., \& Day, L. ( 2012 ) A behavioral test of Horney's linkage between authenticity and aggression: people living authentically are lesslikely to respond aggressively in unfair situations. Personality and Individual Differences, 52, 41-44.

[20] Rosenberg, M. (1965). Society and the adolescent self-image. Princeton. NJ: Princeton University Press.

[21] Watson, D., Clark, L. A., \& Tellegan, A. (1988). Development and validation of brief measures of positive and negative affect: The PANAS scales. Journal of Personality and Social Psychology, 54(6), 1063-1070.

[22] Veit, C., Ware, J. (1983). The structure of psychological distress and wellbeing in general populations. Journal of Consulting and Clinical Psychology, 51, 730-742. 